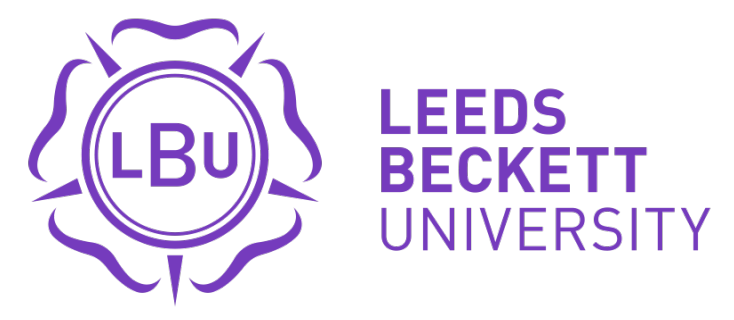

Citation:

Banerjee, G and Rose, A and Briggs, M and Plant, P and Johnson, MI (2021) Could kinesiology taping of the inspiratory muscles help manage chronic breathlessness? An opinion paper. Progress in Palliative Care. pp. 1-5. ISSN 0969-9260 DOI: https://doi.org/10.1080/09699260.2021.1872137

Link to Leeds Beckett Repository record:

https://eprints.leedsbeckett.ac.uk/id/eprint/7613/

Document Version:

Article (Accepted Version)

This is an Accepted Manuscript of an article published by Taylor \& Francis in Progress in Palliative Care on 24th January 2021, available online: http://doi.org/10.1080/09699260.2021.1872137

The aim of the Leeds Beckett Repository is to provide open access to our research, as required by funder policies and permitted by publishers and copyright law.

The Leeds Beckett repository holds a wide range of publications, each of which has been checked for copyright and the relevant embargo period has been applied by the Research Services team.

We operate on a standard take-down policy. If you are the author or publisher of an output and you would like it removed from the repository, please contact us and we will investigate on a case-by-case basis.

Each thesis in the repository has been cleared where necessary by the author for third party copyright. If you would like a thesis to be removed from the repository or believe there is an issue with copyright, please contact us on openaccess@leedsbeckett.ac.uk and we will investigate on a case-by-case basis. 


\section{Could kinesiology taping of the inspiratory muscles help manage chronic breathlessness? An opinion paper.}

Chronic or refractory breathlessness adversely affects quality of life. Current treatment
strategies for managing breathlessness are often inadequate in providing complete
relief. Kinesiology taping is generally used in musculoskeletal practice for preventive
and rehabilitative purposes. Recently, our attention was drawn to the plausible
mechanism(s) and indication for use of kinesiology taping for managing chronic
breathlessness. We present a brief review of the scientific rationale and efficacy of
kinesiology taping for respiratory function related outcomes. Through this publication,
we hope to catalyse discussions amongst palliative care professionals and researchers
on the potential use of kinesiology taping in the management of chronic breathlessness. Keywords: Athletic Tape; Complementary Therapy; Dyspnea; Kinesio Tape; Physical Therapy Modality.

\section{Introduction}

Chronic breathlessness is a multidimensional subjective experience of shortness of breath or breathing discomfort that results from complex interactions between pathophysiological, psychosocial and environmental factors. Chronic breathlessness is commonly manifested in patients with long-term or advanced malignant and non-malignant diseases. Treatment of the underlying cause(s) of chronic or refractory breathlessness is often not possible, while its palliation using pharmacological and non-pharmacological interventions is challenging and at times inadequate in providing complete relief of symptoms [1-3]. The precise physiological mechanism(s) contributing to the perceptual experience of chronic breathlessness is illunderstood. Information arising from activities in mechanoreceptors in the lungs and chest wall, and muscle spindles and tendon organs in respiratory muscles is processed by the cerebrum contributing to respiratory sensations related to muscle tone, proprioception and kinesthesia. It is thought that weakness, fatigue and or mechanical inefficiency of the inspiratory muscles during debilitating diseases contribute to a dissociation between the 
central respiratory drive influencing motor activity and afferent feedback from peripheral receptors situated in the airways, lungs and chest wall, and that this precipitates breathlessness [3-6].

Kinesiology taping is a non-pharmacological method of treatment used in the prevention and rehabilitation of musculoskeletal-related conditions including management of pain [7], cancer-related lymphedema [8-9] and neuromuscular disease-related motor impairment [10-11]. Kinesiology taping involves application of elastic, thin, non-medicated cotton-based water-resistant adhesive tape to the skin using a variety of techniques. Unlike rigid tapes, kinesiology tape can be stretched longitudinally $60 \%$ or more of its resting length and worn continuously for three days or longer if need be to support soft tissues and joints without restricting movements [12]. The "muscle facilitatory" kinesiology taping technique involves stretching adhesive kinesiology tape and applying it to the skin overlying muscles of inspiration; it is claimed that this causes tactile stimulation and concentric pull on superficial soft-tissues leading to modulation of muscle contraction and myofascial tone [13]. There is tentative evidence from small-scale clinical studies that kinesiology taping may improve inspiratory muscle strength and respiratory function, and alleviate breathlessness [14-16]. The purpose of this opinion paper is to review the scientific rationale and efficacy of kinesiology taping for respiratory function, and catalyse discussion amongst palliative care professionals (including physiotherapists and nurses) and researchers on the potential use of kinesiology taping (as an adjunct) in the management of chronic breathlessness.

\section{Scientific rationale}

Research literature on the principles of practice, techniques of application and putative mechanisms of action of kinesiology taping was reviewed by Banerjee et al. [12]. However, the mechanisms by which kinesiology taping may modulate respiratory function and alleviate 
breathlessness remains a subject of speculation due to a paucity of scientific research. The elastic nature of kinesiology tape produces traction, convolutions and mechanical deformation of the skin and superficial layers of viscoelastic connective tissue matrix (fascia) and striated muscle fibres [17-20]. It is claimed that this stimulates low threshold mechanoreceptors in skin, fascia, Golgi tendon organs and muscle spindles, and the resultant volleys of impulses in myelinated A nerve fibres modulates proprioceptive and kinaesthetic awareness, as well as muscle strength and tone. Systematic reviews of clinical studies offer tentative evidence that kinesiology taping may improve pain [7] and functional performance [21] associated with musculoskeletal conditions, although the findings from electromyography studies suggests kinesiology taping has negligible effect on muscle activity and strength [22-24]. Nevertheless, in disease states with weaker inspiratory muscle strength, it seems plausible that the stretch and recoil of kinesiology tape during movements of skin overlying the inspiratory muscles may influence primary afferent fibre activity and / or myofascial tone of inspiratory muscles and associated structures, thereby reducing any mismatch between central respiratory drive and afferent feedback, and thus alleviating breathlessness.

Kinesiology taping may also alleviate breathlessness by providing mechanical support to the structures associated with breathing, i.e., the rib cage, upper abdomen and neck where the primary and accessory inspiratory muscles are located. Breathlessness is a subjective phenomenon driven in part by cognitive appraisals of breathing sensations. It is conceivable that during breathing, sensations associated with the stretch and recoil of kinesiology tape attached to skin of the chest and neck regions provide a kinesthetic reminder that may prompt positional reappraisal such as sitting upright to improve the mechanics of ventilation. This is similar to soft cervical collars that do not restrict neck movements per se, but remind patients with neck pain to limit their neck movements. Likewise, sensations of stretch and recoil of 
kinesiology tape, especially during deep or mindful breathing, may induce positive shifts in perceptual experiences such as a sense that breathing is easier [25].

As part of our ongoing programme of research on this topic, we conducted laboratory experiments using healthy male participants to assess the feasibility of various aspects of research methodology to inform the design of a larger study. We measured the effect of kinesiology taping versus non-elastic taping and no taping controls on inspiratory muscle strength [i.e., sniff nasal inspiratory pressure (SNIP) and maximal inspiratory pressure (MIP)], and forced vital capacity (FVC). We used a cross-over repeated measures design and evaluated aspects of intervention implementation and assessment procedures. Taping interventions were applied to the skin overlying the primary (diaphragm, external intercostal) and accessory (sternocleidomastoid and scalene anterior and middle) muscles of inspiration from their respective origin to insertion points (except for diaphragm) with the length of tissues in a relatively shortened position close to optimal muscle resting length. This technique was employed to attempt maximise the ability of the inspiratory (skeletal) muscles to generate concentric contractions. The accessory muscles were taped together with the primary inspiratory muscles to attempt maximise volitional effort-dependent manoeuvres for assessing SNIP, MIP and FVC.

There was insufficient quantitative data from SNIP, MIP and FVC to determine efficacy, although we found that four out of six participants reported that their neck and ribs felt "fixed" and "supported" by the tape and that it helped them inhale more air. This is consistent with similar improvements in the subjective estimation of ability to breathe after kinesiology taping of the chest region described in a clinical trial [26] and case report [27].

\section{Evidence of efficacy from the research literature}

There is a paucity of primary research evaluating the effects of kinesiology taping on 
respiratory function related outcome measures. Most of the research that exists are small-scale laboratory and clinical studies that lack sufficient detail to appraise the methodological quality.

The findings of explanatory studies using healthy human participants are generally inconsistent. Zübeyir et al. [28] conducted a study without a comparison group and found no significant improvements in MIP and maximal expiratory pressure (MEP) associated with kinesiology taping of the primary muscle of inspiration (diaphragm) $(n=23)$, nor kinesiology taping of the accessory muscles of inspiration (sternocleidomastoid, scalene anterior and middle) and expiration (rectus obliquus externus and internus) ( $\mathrm{n}=24)$. In contrast, Malehorn et al. [29] found that kinesiology taping of the thorax was associated with a greater expiratory tidal volume and a significant improvement in mechanical efficiency compared with no taping control $(n=12)$. Lee et al. [30] compared the combined effect of inspiratory muscle training (IMT) plus kinesiology taping of diaphragm, scalene, sternocleidomastoid and pectoralis minor muscles with IMT alone ( $\mathrm{n}=10$ per group) and found significant improvements in MIP, peak expiratory flow (PEF) and forced expiratory volume in 1 second (FEV1)/FVC from preintervention values in both the groups. There was a significant improvement in minute volume from pre-intervention in kinesiology taping plus IMT group but not in IMT group.

The findings of clinical studies on participants with chronic obstructive pulmonary disease (COPD) are generally positive with investigators concluding that kinesiology taping is beneficial. Tomruk et al. [15] found that kinesiology taping of the respiratory and upper trapezius muscles combined with deep breathing exercises significantly improved PEF and six-minute walk test functional exercise capacity and reduced breathlessness and cough $(n=15)$ compared with deep breathing exercises alone $(n=7)$. Kimothi et al. [31] found significant improvements in PEF after "postural taping" (using non-elastic tape) of the upper back (with erect spine and retracted shoulders) compared with sham taping control ( $\mathrm{n}=17$ per 
group). Daitx et al. [16] compared the effect of standard physiotherapy (PT) plus kinesiology taping of the diaphragm and scalene muscles with standard PT alone ( $\mathrm{n}=31$ per group) and found significant improvements in MIP, MEP, FEV1, PEF and pulse oxygen saturation (SpO2) from pre-intervention values in the kinesiology taping plus standard PT group; however, except for $\mathrm{SpO}$, there were no significant difference in means of other outcomes between the two groups.

Likewise, initial studies provide tentative evidence for improved respiratory function associated with kinesiology taping following stroke and pulmonary surgery. Park et al [32] reported improvements in PEF, FEV1, FVC and chest expansion associated with respiratory muscle taping, chest mobilisation and respiratory muscle taping combined with chest mobilisation ( $\mathrm{n}=10$ per group). However, it was unclear as to whether kinesiology tape was used for the respiratory muscle taping intervention and if the improvements and the difference in means of outcomes were significant. Wang et al. [33] found that kinesiology taping of diaphragm plus breathing exercises significantly increased the tone of stroke-affected upper trapezius, scalene, external oblique abdominal and rectus abdominis muscles compared with the unaffected side whereas breathing exercise alone produced significant increase in the tone of only upper trapezius and external oblique abdominal muscles ( $\mathrm{n}=14$ per group). In postlobectomy (for lung cancer) participants, Imperatori et al. [14] found that kinesiology taping of the chest produced significant improvements in inspiratory volume ( $\mathrm{n}=26$ participants) compared with sham taping control ( $\mathrm{n}=25$ participants).

\section{Future directions}

We believe there is sufficient evidence to merit clinical studies to investigate the acceptability and utility of kinesiology taping for managing chronic breathlessness. Large-scale randomised controlled or pragmatic trials would be ideal, but if that is not feasible case reports and series and prospective cohort studies could be good alternatives. Clinical studies should be 
supported with laboratory studies using healthy participants to elucidate mechanisms, although findings from such studies need to be interpreted in context due to differences in the quality of sensation of breathlessness experienced by healthy participants (e.g., physiologically exercise-induced) versus that experienced by patients with chronic respiratory disease states [34].

Previously, Banerjee et al. reported the findings of a questionnaire survey of healthcare professionals working in oncology and or palliative care settings (mainly registered in the United Kingdom) on the acceptability and utility of kinesiology taping for managing cancer-related symptoms [35]. Skin-related allergic reactions such as skin irritation and rashes were identified as potential adverse events and consequently kinesiology taping was deemed contraindicated or administered with caution to patients with increased skin sensitivity (e.g., following radiotherapy), open wounds or fragile skin. Thus, one should carefully inspect the skin for integrity (e.g., frail / tender skin, wound) and assess for sensitivity (e.g., skin patch test) prior to recruiting participants for kinesiology taping studies trial as not all breathless patients especially in palliative care settings will be fit for kinesiology taping.

\section{Conclusion}

This opinion paper summarises the findings of laboratory and clinical studies on putative mechanisms and effects of kinesiology taping on chronic breathlessness. Kinesiology taping is a low-cost, easy-to-administer complementary therapy that could help in the management of chronic breathlessness in malignant and non-malignant disease states. Current evidence for benefits and safety of kinesiology taping for chronic breathlessness is tentative and there seems merit in conducting further clinical studies.

This project was funded by a PhD student bursary from the Jane Tomlinson Appeal, United Kingdom. No outside contribution was requested or received during the preparation of this article. 
References:

1. Parshall MB, Schwartzstein RM, Adams L, Banzett RB, Manning HL, Bourbeau J, et al. An official American Thoracic Society statement: update on the mechanisms, assessment, and management of dyspnea. American journal of respiratory and critical care medicine 2012;185:435-52.

2. Currow DC, Abernethy AP, Ko DN. The active identification and management of chronic refractory breathlessness is a human right. Thorax 2014;69(4):393-4.

3. Nishino T. Dyspnoea: underlying mechanisms and treatment. British journal of anaesthesia 2011;106:463-74.

4. Gigliotti F. Mechanisms of dyspnea in healthy subjects. Multidisciplinary respiratory medicine. 2010;5:195-01.

5. Burki NK, Lee LY. Mechanisms of dyspnea. Chest 2010;138:1196-201.

6. Georges M, Morawiec E, Raux M, Gonzalez-Bermejo J, Pradat PF, Similowski T, et al. Cortical drive to breathe in amyotrophic lateral sclerosis: a dyspnoea-worsening defence?. European Respiratory Journal 2016;47:1818-28.

7. Banerjee G, Johnson MI. Should kinesiology taping be used to manage pain in musculoskeletal disorders? An evidence synthesis from systematic reviews. Physiother - J Indian Assoc Physiother 2020;14:17-25.

8. Gatt M, Willis S, Leuschner S. A meta-analysis of the effectiveness and safety of kinesiology taping in the management of cancer-related lymphoedema. European journal of cancer care 2017;26:e12510.

9. Kasawara KT, Rossetti Mapa JM, Ferreira V, Added MA, Shiwa SR, Carvas Jr N, et al. Effects of Kinesio Taping on breast cancer-related lymphedema: A meta analysis in clinical trials. Physiotherapy Theory and Practice 2018;34:337-345.

10. Güçhan Z, Mutlu A. The effectiveness of taping on children with cerebral palsy: A systematic review. Developmental Medicine \& Child Neurology 2017;59:26- 30.

11. Cunha AB, Lima-Alvarez CD, Rocha AC, Tudella E. Effects of elastic therapeutic taping on motor function in children with motor impairments: A systematic review. Disability and rehabilitation 2018;40:1609-17.

12. Banerjee G, Briggs M, Johnson MI. Kinesiology taping as an adjunct for pain management: A review of literature and evidence. Indian Journal of Pain 2016;30:1517.

13. Kase K, Wallis J, Kase T, KTAI, McDuffie M (2013): Clinical therapeutic applications of the kinesio taping method - 3rd edition. Kinesio USA, LLC. 
14. Imperatori A, Castiglioni M, Gasperini L, Borrelli J, Grande A, Nardecchia E, et al. F-034 kinesiology taping improves recovery of ventilatory function after thoracotomy lobectomy for lung cancer. Interactive CardioVascular and Thoracic Surgery 2017;25(suppl_1).

15. Tomruk M, Keleş E, Özalevli S, Alpaydın AÖ. Effects of thoracic kinesio taping on pulmonary functions, respiratory muscle strength and functional capacity in COPD patients: a pilot randomized controlled study. European Respiratory Journal 2017;50:PA1534 (DOI: 10.1183/1393003.congress-2017.PA1534)

16. Daitx RB, Dos Santos K, Dohnert MB, da Silva TD, Silva JD. Limited utility of Kinesio Taping ${ }^{\circledR}$ in the physiotherapy treatment for patients with chronic obstructive pulmonary disease exacerbation. Physiotherapy theory and practice 2018;34:741-6.

17. Pamuk U, Yucesoy CA. MRI analyses show that kinesio taping affects much more than just the targeted superficial tissues and causes heterogeneous deformations within the whole limb. Journal of Biomechanics 2015;48:4262-70.

18. Cimino S, Beaudette S, Brown S. Kinesio taping influences the mechanical behaviour of the skin of the low back: A possible pathway for functionally relevant effects. J Biomech 2018;67:150-56.

19. Stecco C, Macchi V, Porzionato A, Duparc F, De Caro R. The fascia: The forgotten structure. Ital J Anat Embryol 2011;116:127-38.

20. Findley T, Chaudhry H, Dhar S. Transmission of muscle force to fascia during exercise. J Bodyw Mov Ther 2015;19:119-23.

21. Wang Y, Gu Y, Chen J, Luo W, He W, Han Z, et al. Kinesio taping is superior to other taping methods in ankle functional performance improvement: a systematic review and meta-analysis. Clinical rehabilitation 2018;32:1472-81.

22. Cai C, Au I, An W, Cheung R. Facilitatory and inhibitory effects of Kinesio tape: Fact or fad? Journal of science and medicine in sport 2016;19:109-12.

23. Serrão JC, Mezêncio B, Claudino JG, Soncin R, Miyashiro PLS, Sousa EP, et al. Effect of 3 Different Applications of Kinesio Taping Denko ${ }^{\circledR}$ on Electromyographic Activity: Inhibition or Facilitation of the Quadriceps of Males During Squat Exercise. Journal of sports science \& medicine 2016;15:403-09.

24. Mak DN, Au IP, Chan M, Chan ZY, An WW, Zhang JH, et al. Placebo effect of facilitatory Kinesio tape on muscle activity and muscle strength. Physiotherapy theory and practice 2019;35:157-62. 
25. Petrovic P, Dietrich T, Fransson P, Andersson J, Carlsson K, Ingvar M. Placebo in emotional processing-induced expectations of anxiety relief activate a generalized modulatory network. Neuron 2005;46:957-69.

26. Brockmann R, Klein HM. Pain-diminishing effects of Kinesio ${ }^{\circledR}$ taping after median sternotomy. Physiotherapy theory and practice 2018;34:433-41.

27. Banerjee G, Rose A, Briggs M, Johnson MI. Could kinesiology taping help mitigate pain, breathlessness and abdominal-related symptoms in cancer? British Medical Journal Case Reports 2017;24;2017:bcr2016216695.

28. Zübeyir S, Nilüfer K, Burcu C, Onur A, Bahar K, Ufuk YS, et al. The effect of kinesiology taping on respiratory muscle strength. Journal of Physical Therapy Science 2012;24:241-4.

29. Malehorn K, Hiniker J, Mackey T, Heumann KJ, Murray SR, Pettitt RW. Kinesio Tape ${ }^{\circledR}$ applied to the thorax augments ventilatory efficiency during heavy exercise. International Journal of Exercise Science 2013;6:157-63.

30. Lee M, Kim M, Ahn C. Impact of Concurrent Inspiratory Muscle Training and Tape on Inspiratory Muscle Strength, Endurance and Pulmonary Function. Journal of The Korean Society of Integrative Medicine 2014;2:65-73.

31. Kimothi S, Nambiar V, Yadav B. Immediate effects of Taping of Upper Back on Peak Expiratory Flow Rate (PEFR) in Stable Chronic Obstructive Pulmonary Disease (COPD) Subjects. Indian Journal of Physiotherapy and Occupational Therapy 2013;7:265-69.

32. Park SJ, Kim SH, Min KO. Effects of Joint Mobilization and Respiratory Muscle Taping on Pulmonary Function and Chest Expansion Ability in Patients with Chronic Stroke. Journal of International Academy of Physical Therapy Research 2017;8:1229-34

33. Wang JS, Cho KH, Park SJ. The immediate effect of diaphragm taping with breathing exercise on muscle tone and stiffness of respiratory muscles and $\mathrm{SpO} 2$ in stroke patient. Journal of physical therapy science 2017;29:970-3.

34. Smith J, Albert P, Bertella E, Lester J, Jack S, Calverley P. Qualitative aspects of breathlessness in health and disease. Thorax 2009;64:713-8.

35. Banerjee G, Briggs M, Rose A, Johnson MI. The use of kinesiology taping for the management of symptoms and complications in the cancer care continuum by healthcare professionals: Findings from questionnaire survey and stakeholder event. Progress in Palliative Care 2019;27:301-9. 